\title{
A novel nomogram to predict the risk of anastomotic leakage in patients after oesophagectomy
}

\author{
Chengya Huang ${ }^{\dagger}$, Haixia Yao ${ }^{\dagger}$, Qi Huang, Huijie Lu, Meiying Xu and Jingxiang Wu*
}

\begin{abstract}
Background: Anastomotic leakage is a dangerous postoperative complication of oesophageal surgery. The present study aimed to develop a simple and practical scoring system to predict the risk of anastomotic leakage after oesophageal resection.

Methods: A consecutive series of 330 patients who underwent oesophageal cancer surgery from January 2016 to January 2018 at the Shanghai Chest Hospital were included to develop a prediction model. Anastomotic leakage was evaluated using oesophagography, computed tomography, or flexible endoscopy. Least absolute shrinkage and selection operator regression based on a generalized linear model was used to select variables for the anastomotic leakage risk model while avoiding overfitting. Multivariable logistic regression analysis was applied to build forest plots and a prediction model. The concordance index or the area under the curve was used to judge the discrimination, and calibration plots verified the consistency. Internal validation of the model was conducted, and the clinical usefulness and threshold screening of the model were evaluated by decision curve analysis.
\end{abstract}

Results: The factors included in the predictive nomogram included Sex, diabetes history, anastomotic type, reconstruction route, smoking history, CRP level and presence of cardiac arrhythmia. The model displayed a discrimination performance with a concordance index of 0.690 (95\% confidence interval: 0.620-0.760) and good calibration. A concordance index value of 0.664 was maintained during the internal validation. The calibration curve showed good agreement between the actual observations and the predicted results.

Conclusion: The present prediction model, which requires only seven variables and includes Sex, diabetes history, anastomotic type, reconstruction route, smoking history, CRP level and presence of cardiac arrhythmia, may be useful for predicting anastomotic leakage in patients after oesophagectomy.

Keywords: Oesophagus operation, Anastomotic leakage, Predictors, Nomogram

\section{Background}

Anastomotic leakage (AL) is one of the most common serious complications after oesophageal surgery and causes prolonged hospital stay, intensive care unit (ICU) admission, and even mortality [1-5]. The incidence of

\footnotetext{
* Correspondence: wjx1132@163.com

${ }^{+}$Chengya Huang and Haixia Yao contributed equally to this work. Department of Anaesthesiology, Shanghai Chest Hospital, Shanghai Jiao Tong University, No. 241 Huaihai Rd. West, Shanghai, China
}

AL is approximately $6-24 \%$ in patients undergoing oesophagogastrostomy $[2,6]$, with an increased postoperative mortality rate of $7.2-18.2 \%$ compared with that of $3.1-$ $6.2 \%$ in patients without leakage. The cost burden was two-times higher for high-grade leakages in an analysis of cervical oesophagogastric anastomotic leaks after transhiatal oesophagectomy [7]. The early detection of $\mathrm{AL}$ is crucial since delayed treatment is associated with significant morbidity, a prolonged hospital stay, and

(c) The Author(s). 2020 Open Access This article is licensed under a Creative Commons Attribution 4.0 International License, which permits use, sharing, adaptation, distribution and reproduction in any medium or format, as long as you give appropriate credit to the original author(s) and the source, provide a link to the Creative Commons licence, and indicate if changes were made. The images or other third party material in this article are included in the article's Creative Commons licence, unless indicated otherwise in a credit line to the material. If material is not included in the article's Creative Commons licence and your intended use is not permitted by statutory regulation or exceeds the permitted use, you will need to obtain permission directly from the copyright holder. To view a copy of this licence, visit http://creativecommons.org/licenses/by/4.0/ The Creative Commons Public Domain Dedication waiver (http://creativecommons.org/publicdomain/zero/1.0/) applies to the data made available in this article, unless otherwise stated in a credit line to the data. 
mortality. The common risk factors for postoperative AL are generally believed to be Sex, age, and the general condition of the patient (long-term malnutrition in patients with oesophageal cancer and a state of negative nitrogen balance, which is often accompanied by chronic wasting diseases such as anaemia and hypoproteinaemia that arise from the body's poor tolerance to surgery). Moreover, the anastomotic type, anastomotic approach, anastomotic site, anastomotic tension, blood supply to the anastomotic region, intrathoracic infection, and postoperative digestive tract emptying are also related to $\mathrm{AL}$ [8]. Since there are many relevant risk factors, the use of accurate predictive tools and early intervention may be the most effective preventive actions for postoperative AL. Although relevant guidelines for this research area exist both internationally and domestically, there is a lack of validated tools based on national characteristics. This study aimed to develop a simple and effective prediction tool to perioperatively estimate the risk of AL for oesophageal cancer patients using readily available characteristics at the start of therapy.

\section{Methods}

\section{Patients and data collection}

This retrospective cohort study was approved by the institutional review board of Shanghai Chest Hospital and Shanghai Jiao Tong University's Ethics Committee, and the requirement to obtain informed consent was waived. A total of 330 patients underwent three-incision oesophageal surgery. The data were collected from January 2016 to January 2018. The demographic characteristics, clinical features and auxiliary examinations of the patients were recorded in detail.

\section{Protocol}

According to the reference literature and relevant clinical experience, a total of 45 variables with potential connections to AL were included $[9,10]$. The study was completed using an independent database from the hospital, and the database was automatically updated. At our centre, if AL was first suspected on the basis of factors such as persistent fever, leucocytosis, unexplained pneumonia, abnormal chest tube drainage that included faecal contents, and local inflammation of a cervical wound, then the leak could be visualized by contrast oesophagography, computed tomography, or flexible endoscopy [11].

The following variables were recorded:

(i) Clinical examination: Sex, age at surgery, body mass index (BMI), cardiac ultrasound, liver and kidney function, blood biochemistry, cardiovascular risk factors (smoking history (at least 10 cigarettes a day for more than 5 years), diabetes mellitus (DM) history (diagnosed as type $2 \mathrm{DM}$ for at least one year before surgery according to the WHO criteria and receiving oral antidiabetic drugs or insulin), chronic hypertension and coronary heart disease (diagnosed by a physician and currently taking antihypertensive, antiplatelet or antianginal drugs or having a history of myocardial revascularization), location of oesophageal tumours and preoperative neoadjuvant chemoradiotherapy (nCRT).

(ii) Perioperative data: surgical method, duration of the procedure, American Society of Anesthesiologists (ASA) score, anastomotic type, reconstruction route, duration of anaesthesia, intubation method, oxygen saturation level, temperature, hypotension status, hypertension status, presence of cardiac arrhythmia (new-onset intraoperative cardiac arrhythmia, such as atrial fibrillation, ventricular tachycardia, frequent multisource ventricular premature beats and severe paroxysmal supraventricular tachycardia that needed drug or electrical conversion therapy) and the change in central venous pressure when entering the thoracic cavity.

Disease stages and tumour types were not included in the variable screening for the model, although they were reported to be important risk factors. However, in clinical practice, the results of the pathological tumourmetastasis-node (TMN) classification of tumours are reported relatively late. Considering that this study mainly focused on the early prediction capabilities of the model, the parameters selected were mainly preoperative and intraoperative indicators.

\section{Operations}

Our standard procedures consisted of a threeincision surgery (thoracic cavity, abdominal stations and cervical), reconstruction with a gastric tube through a posterior mediastinal route or retrosternal route, and anastomosis in the cervical incision. The thoracic phase consisted of either thoracotomy or video-assisted or robot-assisted thoracoscopic surgery. Lymph node dissection was based on total twofield lymphadenectomy, which included (1) all nodes and periesophageal tissues below the level of the carina to the celiac trifurcation and (2) all superior mediastinal nodes along the recurrent laryngeal nerve to the lower poles of the thyroid. Lymph nodes in the supraclavicular fossa were not routinely removed. The abdominal phase was performed using laparotomy or laparoscopy. Patients received either a hand-sewn or circular-stapled cervical oesophagogastric anastomosis. 


\section{Statistical analysis}

In the first step, the least absolute shrinkage and selection operator (LASSO) regression model, which is based on a generalized linear model, was used to identify suitable predictive features [12]. Second, multivariable logistic regression analysis was performed to build a forest plot and a prediction model. The model that included all candidate predictors selected from the LASSO analysis was presented as a nomogram. Third, we validated the discrimination of the nomogram with Harrell's concordance index (C-index) and the area under the curve (AUC). To assess the calibration of the nomogram, biascorrected calibration plots were used to compare the actual risk and predicted risk. Meanwhile, decision curve analysis (DCA) was used to estimate the clinical usefulness and net benefit of the nomogram [13]. Finally, the nomogram was internally validated using 1000 bootstrap resamples and calculating a relatively corrected $\mathrm{C}$-index.

All $P$-values less than 0.05 were considered statistically significant, and the statistical significance levels were two-sided. In this study, the data were analysed with $\mathrm{R}$ software (Version 3.5.2; https://www.R-project.org). The packages included glmnet, rms, ROCR, rmda and forestplot.

\section{Results}

\section{Patient characteristics}

Baseline characteristics, including demographics, disease, and treatment characteristics of the patients, are summarized in Table 1. A total of 330 patients (263 males and 67 females; mean age $62.83 \pm 7.22$ years [range $42-$ 83 years]) who underwent oesophageal surgery were enrolled from January 2016 to January 2018. Among all the patients, 97.3\% (321/330) had oesophageal squamous cell carcinoma, and 2.7\% (9/330) had adenocarcinoma. Oesophagectomies were performed by 10 specialist surgeons. The surgical method was jointly decided after discussion by the surgical team, and standard operating procedures were used. Patients were divided into an AL group and a non-AL group.

\section{Variable selection}

LASSO regression analysis can be used to reduce the dimensionality of complex variables and increase the accuracy of a model. Finally, baseline characteristics that included 45 features were reduced to 7 potential predictors (Fig. 1). The strongest predictors included Sex, DM history, anastomotic type, reconstruction route, smoking history, CRP level and presence of cardiac arrhythmia (Table 2).

\section{Development of a novel prediction model}

The weights and points associated with the seven variables are shown in the forest plots (Fig. 2a). Additionally,
Table 1 Differences between demographic and clinical characteristics of $A L$ and non-AL groups

\begin{tabular}{|c|c|c|c|}
\hline Characteristics & $\begin{array}{l}\mathrm{AL} \\
(n=79, \mathrm{n} \%)\end{array}$ & $\begin{array}{l}\text { Non- AL } \\
(n=251, n \%)\end{array}$ & $\begin{array}{l}\text { Population } \\
(n=330, n \%)\end{array}$ \\
\hline \multicolumn{4}{|l|}{$\overline{\text { Sex }}$} \\
\hline male & $68(86.08)$ & $195(77.69)$ & $263(79.70)$ \\
\hline female & $11(13.92)$ & $56(22.31)$ & $67(20.30)$ \\
\hline \multicolumn{4}{|l|}{ Age (years) } \\
\hline$<65$ & $49(62.03)$ & $144(57.37)$ & $193(58.48)$ \\
\hline$\geq 65$ and $<75$ & $27(34.18)$ & $93(37.05)$ & $120(36.36)$ \\
\hline$\geq 75$ & $3(3.80)$ & $14(5.58)$ & $17(5.15)$ \\
\hline \multicolumn{4}{|l|}{ Pathology } \\
\hline squamous & $78(98.73)$ & $243(96.81)$ & $321(97.27)$ \\
\hline adenocarcinoma & $1(1.27)$ & $8(3.19)$ & $9(2.73)$ \\
\hline \multicolumn{4}{|c|}{ Pathologic tumour stage } \\
\hline Stage 0 & $0(0)$ & $0(0)$ & $0(0)$ \\
\hline Stage 1 & $9(11.39)$ & $51(20.32)$ & $60(18.18)$ \\
\hline Stage II & $36(45.57)$ & $109(43.43)$ & $145(43.94)$ \\
\hline Stage III & $32(40.51)$ & $86(34.26)$ & $118(35.76)$ \\
\hline Stage IV & $2(2.53)$ & $5(1.99)$ & $7(2.12)$ \\
\hline \multicolumn{4}{|l|}{ Surgery method } \\
\hline robot & $27(34.18)$ & $84(33.47)$ & $111(33.64)$ \\
\hline thoracoscopy & $31(39.24)$ & $122(48.61)$ & $153(46.36)$ \\
\hline open & $21(26.58)$ & $45(17.93)$ & $66(20)$ \\
\hline HBP & $7(8.86)$ & $21(8.37)$ & $28(8.48)$ \\
\hline DM & $12(15.19)$ & $20(7.97)$ & $32(9.70)$ \\
\hline CHD & $3(3.80)$ & $3(1.20)$ & $6(1.82)$ \\
\hline Smoking & $12(15.19)$ & $14(5.58)$ & $26(7.88)$ \\
\hline nCRT & $13(16.46)$ & $28(11.16)$ & $41(12.42)$ \\
\hline \multicolumn{4}{|l|}{ Location } \\
\hline upper & $10(12.66)$ & $32(12.75)$ & $42(12.73)$ \\
\hline middle & $47(59.49)$ & $163(64.94)$ & $210(63.64)$ \\
\hline lower & $22(27.85)$ & $56(22.31)$ & $78(23.64)$ \\
\hline \multicolumn{4}{|l|}{ BMI $\left(\mathrm{kg} / \mathrm{m}^{2}\right)$} \\
\hline$<18.5$ & $7(8.86)$ & $16(6.37)$ & $23(6.97)$ \\
\hline$\geq 18.5$ and $<24$ & $39(49.37)$ & $148(58.96)$ & $187(56.67)$ \\
\hline$\geq 24$ and $<28$ & $27(34.18)$ & $77(30.68)$ & $104(31.52)$ \\
\hline$\geq 28$ & $6(7.59)$ & $10(3.98)$ & $16(4.85)$ \\
\hline \multicolumn{4}{|l|}{ ASA } \\
\hline I & $1(1.27)$ & $5(1.99)$ & $6(1.82)$ \\
\hline$\|$ & $69(87.34)$ & $222(88.45)$ & $291(88.18)$ \\
\hline III & 9 (11.39) & $24(9.56)$ & $33(10)$ \\
\hline Blood ( $\geq 400 \mathrm{ml}$ ) & $3(3.80)$ & $11(4.38)$ & $14(4.24)$ \\
\hline \multicolumn{4}{|l|}{ Surgery time (min) } \\
\hline$<180$ & $2(2.53)$ & $12(4.78)$ & $14(4.24)$ \\
\hline$\geq 180$ and 300 & $50(63.29)$ & $174(69.32)$ & $224(67.88)$ \\
\hline
\end{tabular}


Table 1 Differences between demographic and clinical characteristics of AL and non-AL groups (Continued)

\begin{tabular}{clll}
\hline Characteristics & $\mathrm{AL}$ & Non- AL & Population \\
& $(n=79, \mathrm{n} \%)$ & $(n=251, \mathrm{n} \%)$ & $(n=330, \mathrm{n} \%)$ \\
\hline$\geq 300$ & $27(34.18)$ & $65(25.90)$ & $92(27.88)$
\end{tabular}

\section{Thoracic surgery time}

$\begin{array}{llll}<60 & 9(11.39) & 25(9.96) & 34(10.30) \\ \geq 60 \text { and }<120 & 49(62.03) & 168(66.93) & 217(65.76) \\ \geq 120 & 21(26.58) & 58(23.11) & 79(23.94) \\ \text { Transfer } & 6(7.59) & 10(3.98) & 16(4.85)\end{array}$

Anastomotic type

\begin{tabular}{|c|c|c|c|}
\hline stapled & $44(55.70)$ & $186(74.10)$ & $230(69.70)$ \\
\hline hand-sewn & $35(44.30)$ & $65(25.90)$ & $100(30.30)$ \\
\hline \multicolumn{4}{|l|}{ Route reconstruction } \\
\hline retrosternal & $44(55.70)$ & $80(31.87)$ & $124(37.58)$ \\
\hline posterior mediastinum & $35(44.30)$ & $171(68.13)$ & $206(62.42)$ \\
\hline
\end{tabular}

\begin{tabular}{|c|c|c|c|}
\hline ardiac ultrasound & & & \\
\hline abnormal & $23(29.11)$ & $68(27.09)$ & $91(27.58)$ \\
\hline
\end{tabular}

$\begin{array}{llll}\mathbf{T P}(\mathbf{g} / \mathbf{L}) & & & \\ <65 & 8(10.13) & 18(7.17) & 26(7.88) \\ \geq 65 & 71(89.87) & 233(92.83) & 304(92.12)\end{array}$

ALB (g/L)

$$
<35
$$$$
\geq 35
$$

PAB (g/L)

$<0.2$

$\geq 0.2$

ALT (U/L)

$<9$

$\geq 9$ and $<50$

$\geq 50$

AST (U/L)

$<15$

$\geq 15$ and $<40$

$\geq 40$

Urea $(\mathrm{mmol} / \mathrm{L})$

$$
\begin{aligned}
& <3.1 \\
& \geq 3.1 \text { and }<9.5 \\
& \geq 9.5
\end{aligned}
$$

\section{CREA ( $\mathrm{mmol} / \mathrm{L})$}

$$
\begin{aligned}
& <57 \\
& \geq 57 \text { and }<111 \\
& \geq 111
\end{aligned}
$$

\begin{tabular}{|c|c|c|c|}
\hline Characteristics & $\begin{array}{l}\mathrm{AL} \\
(n=79, n \%)\end{array}$ & $\begin{array}{l}\text { Non- AL } \\
(n=251, n \%)\end{array}$ & $\begin{array}{l}\text { Population } \\
(n=330, n \%)\end{array}$ \\
\hline$\geq 5.9$ & $16(20.25)$ & 48 (19.12) & 64 (19.39) \\
\hline \multicolumn{4}{|l|}{ PCT (ng/ml) } \\
\hline $0-0.05$ & $67(84.81)$ & 219 (87.25) & 286 (86.67) \\
\hline$>0.05$ & $12(15.19)$ & $32(12.75)$ & 44 (13.33) \\
\hline \multicolumn{4}{|l|}{ D-dimer (mg/L) } \\
\hline$<0.55$ & $64(81.01)$ & 195 (77.69) & 259 (78.48) \\
\hline$\geq 0.55$ & 15 (18.99) & $56(22.31)$ & 71 (21.52) \\
\hline \multicolumn{4}{|l|}{ CRP (mg/L) } \\
\hline$\leq 10$ & $70(88.61)$ & $238(94.82)$ & 308 (93.33) \\
\hline$>10$ & 9 (11.39) & $13(5.18)$ & $22(6.67)$ \\
\hline \multicolumn{4}{|l|}{ ESR $(\mathrm{mm} / \mathrm{h})$} \\
\hline$\leq 40$ & $62(78.48)$ & 198 (78.88) & 260 (78.79) \\
\hline$>40$ & 17 (21.52) & $53(21.11)$ & $70(21.21)$ \\
\hline \multicolumn{4}{|l|}{ PLT (10^9/L) } \\
\hline$<125$ & $8(10.13)$ & $16(6.37)$ & $24(7.27)$ \\
\hline$\geq 125$ and $<350$ & $69(87.34)$ & $224(89.24)$ & 293 (88.79) \\
\hline$\geq 350$ & $2(2.53)$ & $11(4.38)$ & 13 (3.94) \\
\hline
\end{tabular}

\section{Glu (mmol/L)}

$$
\begin{aligned}
& <4.3 \\
& \geq 4.3 \text { and }<5.9
\end{aligned}
$$

$11(13.92) \quad 38(15.14) \quad 49(14.85)$

$68(86.08) \quad 213(84.86) \quad 281(85.15)$
Table 1 Differences between demographic and clinical characteristics of AL and non-AL groups (Continued)

\section{$\mathrm{Hb}(\mathrm{g} / \mathrm{L})$}

$<130$

$\geq 130$ and $<175$

$\begin{array}{lll}17(21.52) & 47(18.73) & 64(19.39) \\ 61(77.22) & 200(79.68) & 261(79.09) \\ 1(1.27) & 4(1.59) & 5(1.52)\end{array}$

$$
\geq 175
$$

HCT (\%)

$$
\begin{aligned}
& <40 \\
& \geq 40 \text { and }<50
\end{aligned}
$$$$
\geq 50
$$

Anaesthesia time ( $\min )$

$$
\begin{aligned}
& <300 \\
& \geq 300 \text { and }<420 \\
& \geq 420
\end{aligned}
$$

Anaesthesia method

$$
\text { GA }
$$

$\begin{array}{lll}18(22.78) & 43(17.13) & 61(18.48) \\ 56(70.89) & 191(76.10) & 247(74.85) \\ 5(6.33) & 17(6.77) & 22(6.67) \\ & & \\ 31(39.24) & 99(39.44) & 130(39.39) \\ 40(50.63) & 143(56.97) & 183(55.45) \\ 8(10.13) & 9(3.59) & 17(5.15) \\ 75(94.94) & 238(94.82) & 313(94.85) \\ 4(5.06) & 13(5.18) & 17(5.15) \\ & & \\ 34(43.04) & 79(31.47) & 113(34.24) \\ 17(21.52) & 79(31.47) & 96(29.09) \\ 28(35.44) & 93(37.05) & 121(36.67) \\ & & \\ 68(86.08) & 220(87.65) & 288(87.27) \\ 11(13.92) & 31(12.35) & 42(12.73)\end{array}$

Intubation

DLT

Tracheal + BBT

Tracheal tube

$$
\begin{gathered}
\mathrm{SPO}_{2}(\%) \\
<90 \\
\geq 90
\end{gathered}
$$

\section{$\mathrm{EtCO}_{2} \_\mathrm{max}(\mathrm{mmHg})$}

$$
\begin{aligned}
& <60 \\
& \geq 60
\end{aligned}
$$$$
77(97.47) \quad 239(95.22) \quad 316(95.76)
$$$$
2(2.53) \quad 12(4.78) \quad 14(4.24)
$$ 
Table 1 Differences between demographic and clinical characteristics of AL and non-AL groups (Continued)

\begin{tabular}{llll}
\hline Characteristics & $\begin{array}{l}\mathrm{AL} \\
(n=79, \mathrm{n} \%)\end{array}$ & $\begin{array}{l}\text { Non- AL } \\
(n=251, \mathrm{n} \%)\end{array}$ & $\begin{array}{l}\text { Population } \\
(n=330, \mathrm{n} \%)\end{array}$ \\
\hline $\begin{array}{llll}\mathrm{PaCO}_{\mathbf{2}} \text { (mmHg) } \\
<65\end{array}$ & $64(81.01)$ & $194(77.29)$ & $258(78.18)$ \\
$\quad \mathbf{6 5}$ & $15(18.99)$ & $57(22.71)$ & $72(21.82)$
\end{tabular}

Protective ventilation

$\begin{array}{llll}\text { no } & 47(59.49) & 143(56.97) & 190(57.58) \\ \quad \text { yes } & 32(40.51) & 108(43.03) & 140(42.42) \\ \begin{array}{l}\text { Temperature }\left({ }^{\circ} \mathrm{C}\right) \\ \quad<36.0\end{array} & 55(69.62) & 173(68.92) & 228(69.09) \\ \geq 36.0 & 24(30.38) & 78(31.08) & 102(30.91)\end{array}$

Hypotension

$\begin{array}{llll}\text { no } & 73(92.41) & 232(92.43) & 305(92.42) \\ <\text { SBP } 90 \mathrm{mmHg}, \geq 10 \mathrm{~min} & 5(6.33) & 17(6.77) & 22(6.67) \\ >\text { SBP } 90 \mathrm{mmHg}, \geq 30 \mathrm{~min} & 1(1.27) & 2(0.80) & 3(0.91)\end{array}$

\section{Hypertension}

$\begin{array}{llll}\text { no } & 63(79.75) & 199(79.28) & 262(79.39) \\ >\text { SBP160 mmHg, } \geq 10 \mathrm{~min} & 10(12.66) & 42(16.73) & 52(15.76) \\ >\text { SBP160 mmHg, } \geq 30 \mathrm{~min} & 6(1.82) & 10(3.98) & 16(4.85)\end{array}$

Cardiac arrhythmia

\begin{tabular}{llll} 
no & $69(87.34)$ & $240(95.62)$ & $309(93.64)$ \\
yes & $10(12.66)$ & $11(4.38)$ & $21(6.36)$ \\
CVP change $\left(\mathbf{c m H}_{\mathbf{2}} \mathbf{O}\right)$ & & & \\
$0-5$ & $9(11.39)$ & $30(11.95)$ & $39(11.82)$ \\
$5-10$ & $35(44.30)$ & $104(41.43)$ & $139(42.12)$ \\
$10-15$ & $28(35.44)$ & $90(35.86)$ & $118(35.76)$ \\
$\geq 15$ & $7(8.86)$ & $27(10.76)$ & $34(10.30)$ \\
\hline
\end{tabular}

Abbreviations: $H B P$ hypertension, $D M$ diabetes, $C H D$ coronary heart disease, $T P$ total protein, $A L B$ albumin, $P A B$ prealbumin, $A L T$ alanine aminotransferase, $A S T$ aspartate transaminase, $P C T$ procalcitonin, $C R P$ C-reactive protein, $E S R$ erythrocyte sedimentation rate, $P L T$ platelet count, $H b$ haemoglobin, $H C T$ red blood cell specific volume, CVP central venous pressure, $n C R T$ neoadjuvant chemoradiotherapy

all potential predictors in Table 2 were used to develop a prediction model for the risk of $\mathrm{AL}$ and are presented as the nomogram (Fig. 2b).

\section{How to use this nomogram}

As seen in Fig. 2b, for one patient, the corresponding point is derived from each variable axis. The sum of the points is located on the total points axis and corresponds to a probability shown below (risk of AL). For example, if a male smoker with a hand-sewn anastomosis undergoes surgery and he has a sudden new onset of atrial fibrillation, the total points would be 248 , and the risk of AL would be $73 \%$. This would help us to treat patients for AL and to arrange follow-up treatment.

\section{Evaluation of the model}

The predictive nomogram achieved a C-index of 0.690 (95\% confidence interval (CI): 0.620-0.760), which was confirmed to be 0.664 through internal validation, suggesting that the model has moderate discrimination. A calibration curve was based on the actual incidence and predicted incidence. The bias-corrected line was the fitted line of the predicted and measured incidence. For convenience during comparisons, an ideal dotted line was added to the figure. The dotted line represents $y=x$, which means that the predicted and measured rates are exactly the same. The calibration curve of the nomogram to predict AL risk after oesophageal surgery demonstrated good agreement in this cohort (Fig. 3a). The accuracies of the risk models were also compared using area under the receiver operating characteristic (ROC) curve (AUC $=0.690)$ analysis (Fig. $3 b)$.

\section{DCA for the prediction model}

As previously described [14], DCA was used to determine whether the AL prediction model-based decisions were clinically useful compared with the default strategies for patients after oesophagectomy. DCA is based on a continuum of potential thresholds risk ( $x$-axis, the harm-to-benefit ratio considering incorrect model-based decisions due to false negatives and false positives) and the net benefit of using the model to risk stratify patients ( $y$-axis, potential benefit minus potential harm) relative to assuming that no patient will have AL. A model is only clinically useful at the threshold risk if it has a higher net benefit than treating all (slope line) and treating no (horizontal line) patients. If a model has a lower net benefit than any default strategy, we consider the model clinically harmful in that threshold risk range, as one of the default strategies leads to better decisions.

As shown in Fig. 4, DCA graphically showed the clinical usefulness of the nomogram to predict AL risk. The graph shows the excepted net benefit per patient to predict the risk of AL for any patient (red curve). A typical range is $8-74 \%$; that is, within this range of threshold risks, if an intervention based on AL predicts modelbased decisions is clearly beneficial (e.g., delaying surgery to reduce the elevated CRP level), it should be used.

\section{Discussion}

The current study developed a novel tool to predict the risk of AL after oesophageal surgery based on 2 years of data from indigenous Chinese patients. On the one hand, the prediction of the model focused on selecting predictors. When determining variables, the complexity of the model should be adjusted to achieve a balance between overfitting and insufficient fitting. LASSO regression analysis was used instead of univariate analysis to find independent risk factors. We believe that principal 

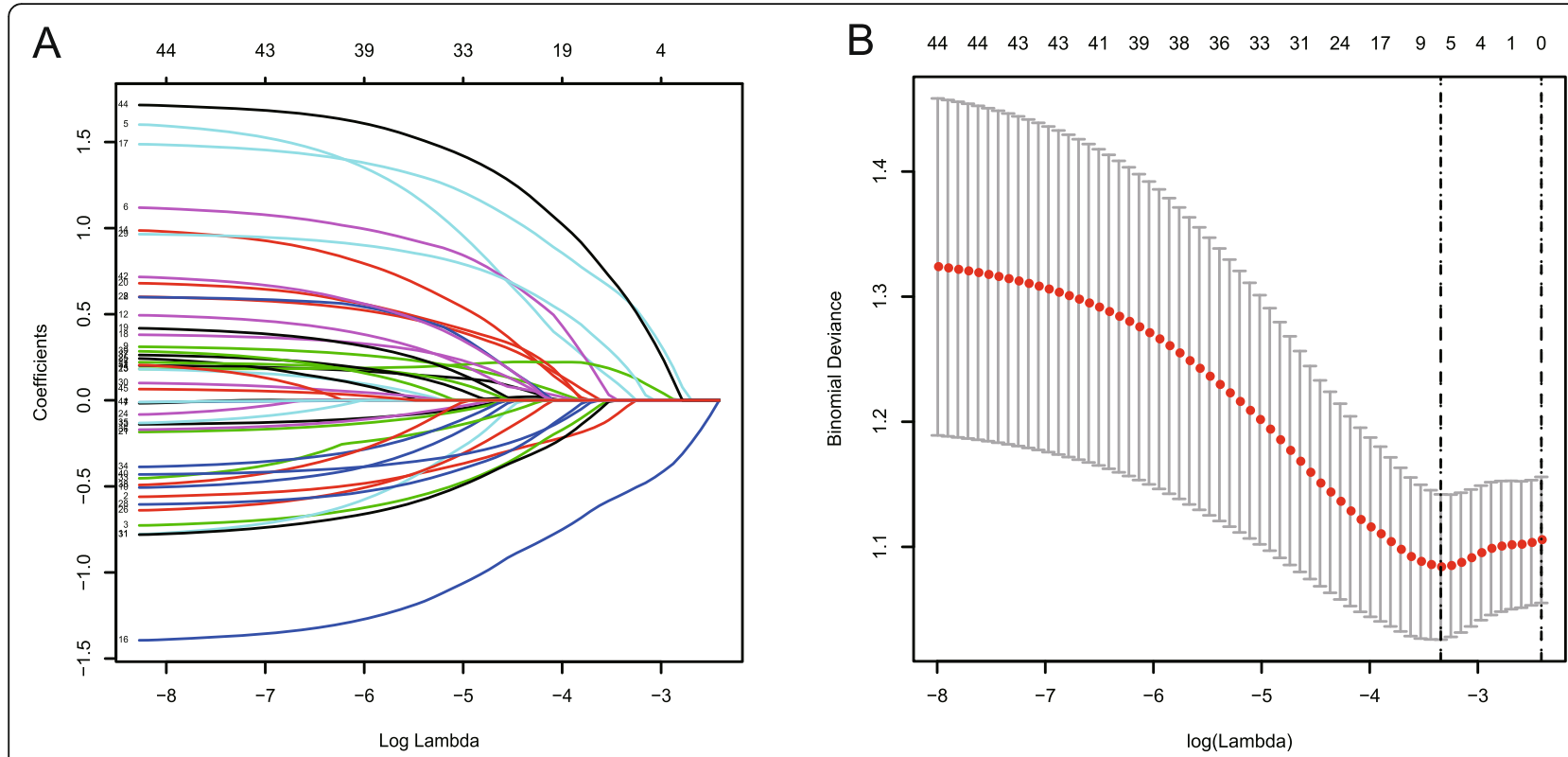

Fig. 1 Predictor selection using a LASSO logistic regression model. a Shrinkage estimation parameter: fivefold cross validation (CV) is the most common repeated sampling method. According to the one standard error (SE) rule, glmnet usually recommends lambda. 1 se instead of lambda.min to identify the model with the best performance but with the fewest number of independent variables. $\mathbf{b}$ Dotted vertical lines were drawn at the optimal values by using the minimum criteria (lambda.min) and 1 SE of the minimum criteria (lambda.1se)

component analysis is only applicable to samples with few dimensions. LASSO is another data dimensionality reduction method, and it is suitable not only for linear data but also nonlinear data. LASSO can directly compress insignificant variable coefficients to 0 [15]. On the other hand, the accuracy and consistency of the model were evaluated in the trial, and the internal verification results showed that the nomogram can be widely used for AL prediction.

Two previous reports have made similar attempts to identify the risk of AL. One study was conducted by Haga $\mathrm{Y}$ et al. [16] in 2011, who created a prediction scoring system, "Estimation of Physiologic Ability and Surgical Stress" (E-PASS), to predict the postoperative morbidity and mortality of elective gastrointestinal surgery. The study included nine variables to calculate a numerical score. However, their research included various kinds of gastrointestinal surgery. There were only 292 oesophageal surgeries among the 6005 cases (4.8\%), which may not fully reflect AL after oesophageal surgery. The other study was conducted in 2012 by Noble F et al. [17], who combined blood-borne inflammatory markers, including postoperative CRP levels, white cell counts and albumin levels, as predictors of AL and major complications. They reported a sensitivity of $95 \%$, a specificity of $49 \%$ and a diagnostic accuracy of 0.801 . The same nomogram was recently validated by Bundred J. et al., who reported an accuracy of 0.77 [18]. However, the three indicators used by Nobel $F$ and Bundred $J$ were laboratory indicators on the 4th day after surgery, which may be closely related to the anastomotic fistula itself. Their

Table 2 Prediction factors for the risk of anastomotic leakage with oesophageal operation

\begin{tabular}{llll}
\hline Intercept and variable & $\beta$ & Prediction model & Odds ratio (95\% Cl) \\
\hline Intercept & & $0.35(0.19-0.63)$ & 0.001 -value \\
Sex (female) & -1.05 & $0.56(0.26-1.14)$ & 0.13 \\
DM & -0.58 & $1.80(0.73-4.24)$ & 0.19 \\
Anastomotic type (hand-sewn) & 0.57 & $1.47(0.78-2.75)$ & 0.23 \\
Reconstruction route (mediastinal) & 0.39 & $0.42(0.23-0.77)$ & $0.004 *$ \\
Smoking & -0.87 & $3.08(1.24-7.50)$ & $0.01 *$ \\
CRP $(>10$ mg/L) & 1.12 & $2.28(0.85-5.92)$ & 0.09 \\
Cardiac arrhythmia & 0.83 & $4.12(1.57-10.72)$ & $0.003 * *$ \\
\hline
\end{tabular}

${ }^{*} P<0.05,{ }^{*} P<0.01,{ }^{* * *} P<0.001$ 


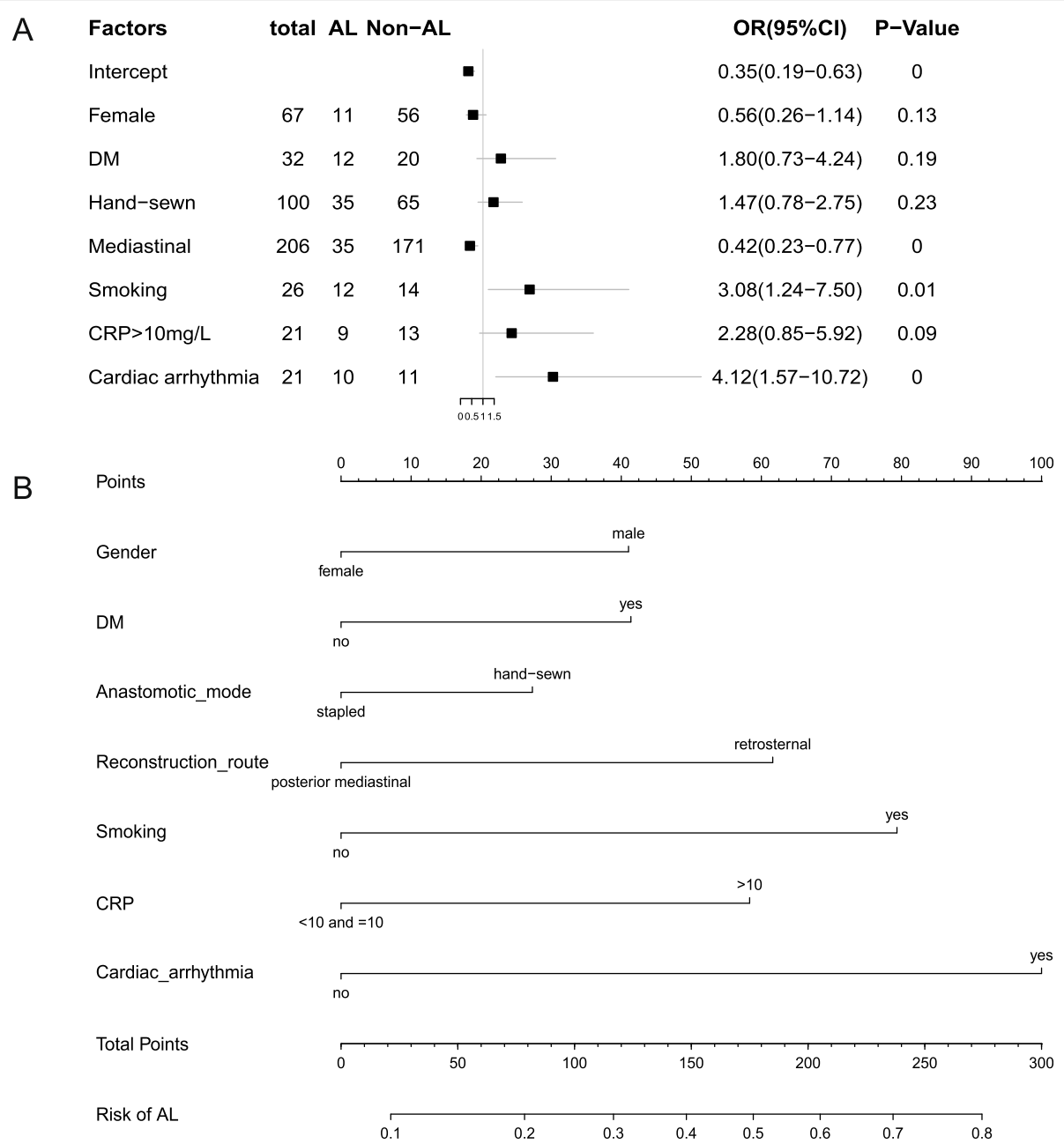

Fig. 2 a Multivariable logistic regression analysis was applied to build the forest plots. $\mathbf{b}$ The developed AL risk nomogram. Note: The AL risk nomogram was developed by incorporating the following characteristics: sex, DM history, anastomotic type, route reconstruction, smoking history, CRP level and presence of cardiac arrhythmia

results can be used well for the treatment 4 days after surgery.

Previous studies have mainly focused on postoperative laboratory biomarker data, which is quite different from our study. The main advantage of the current study is that our nomogram is easier and more intuitive than existing methods, and our nomogram includes different parameters to consider both pre- and intraoperative factors. The current scoring tool is able to clarify the combination of surgical factors and patient factors by focusing on active smoking, CRP levels and intraoperative parameters, such as anastomotic type, reconstruction route and the presence of intraoperative cardiac arrhythmia. In addition, of the 45 empirical clinical parameters, 7 parameters with significant effects in the multivariate analysis were selected, and the weighting of each parameter was significant, which could reflect the significant influence of these factors on the predicted value.

In this study, approximately $24 \%$ of patients experienced AL after surgery. In a previous study, David $\mathrm{T}$ et al. [19] showed that a large number of preoperative comorbidities, advanced pathologic stage, postoperative arrhythmia, history of oesophagogastric surgeries, and active smoking history were risk factors for developing cervical oesophagogastric ALs, while a side-to-side stapled cervical oesophagogastric anastomosis was a protective factor [19]. A meta-analysis revealed that diabetes, preoperative serum albumin $<35 \mathrm{~g} / \mathrm{L}$, respiratory diseases, hypertension, preoperative neoadjuvant radiotherapy, stage III and IV oesophageal cancer, manual anastomosis and posterior sternal neck anastomosis were risk factors for $\mathrm{AL}$ after oesophageal cancer surgery [5]. 

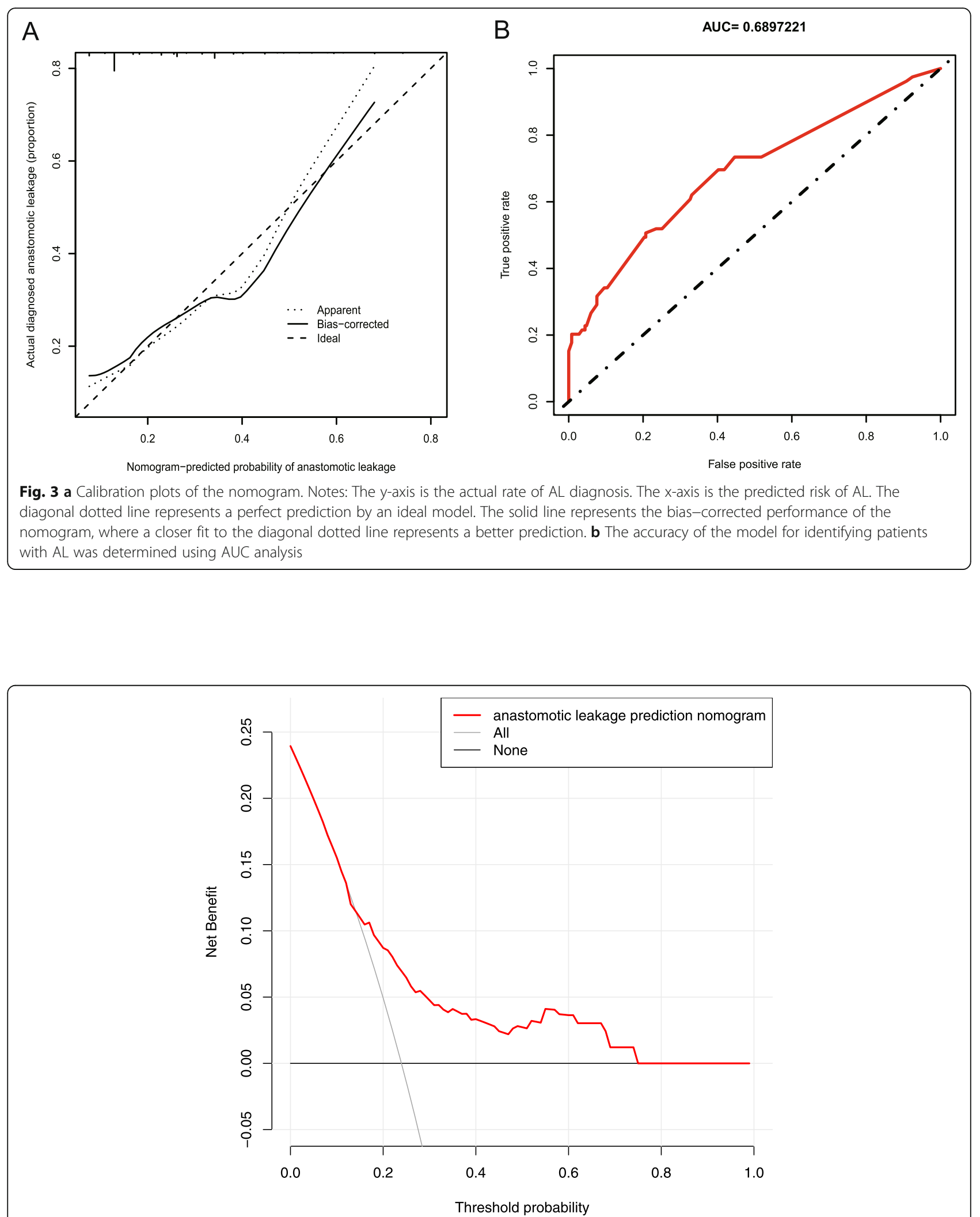

Fig. 4 DCA. Notes: DCA showed the clinical usefulness of the nomogram. The $y$-axis measures the net benefit. The red solid line is the nomogram to predict AL risk. The grey solid line assumes that all patients will develop AL. The black thin solid line assumes that no patients will develop AL. In this analysis, the decision curve provided a larger net benefit across the range of 8 and $74 \%$ 
We agree that patients with lower oesophageal carcinoma who received nCRT cannot be considered in the same way as patients treated for cervical cancer when analysing AL. However, we did not find a statistically significant difference based on the current data when including the factors of nCRT treatment and the location of the tumour (see Table 1). There is still some controversy about nCRT and AL. Although Briel et al. [20] reported that oesophagocolic anastomoses after nCRT were a risk factor for AL results from other studies did not support this finding [21-23].

Despite the fact that $37.2 \%$ of cases were T1-3N1-2M0 and T4aN0-1M0, which were indications for nCRT according to the 2018 Chinese guidelines for diagnosis and treatment of oesophageal carcinoma [24], only $12.4 \%$ received nCRT because the use of nCRT before surgery in patients with locally advanced oesophageal cancer has only been slowly accepted in the last two years in China. Previously, it was believed that nCRT had a significant survival benefit for patients with locally advanced oesophageal cancer. However, nCRT was not recommended for patients with early oesophageal cancer because of its high surgical resection rate, and the addition of nCRT does not improve the R0 resection rate and increases the risk of postoperative death. In addition, even though nCRT appears to be associated with a higher R0 resection rate, there are still people who are reluctant to use preoperative nCRT because they are afraid of missing the appropriate surgical timing due to concerns about disease progression.

Urschel JD [25] and Pierie JP [26] suggested that an insufficient blood supply to the anastomotic stoma was the main risk factor for AL. Cooke found that postoperative arrhythmias that caused a low-flow state predicted leakage based on multivariate analysis [19]. Among our patients, those who experienced intraoperative arrhythmia were predisposed to AL, possibly for the same reason. The surgical approach is divided into a retrosternal reconstruction route and mediastinal reconstruction route. From an anatomical point of view, the length of the incision is longer with the posterior sternal approach than with the mediastinal approach, which inevitably leads to oesophageal free ends. An anastomotic route that is too long could cause excessive anastomotic tension, lack of blood supply to the tissue, and an elevated incidence of AL. Other potential risk factors, including smoking history and diabetic microangiopathy, in theory, may reduce microperfusion of tissues $[19,27]$. The probability of postoperative $\mathrm{AL}$ is higher in men than in women; however, this difference is not clinically significant, which is consistent with the results from Vaporciyan AA [11]. The anastomotic techniques include handsewn anastomosis and device anastomosis. Hand-sewn anastomosis may cause variations in needle spacing and unequal ligation strength, which facilitates anastomotic stoma occurrence. CRP is an inflammatory indicator that can reflect the preoperative inflammatory condition of the body. High preoperative CRP levels may also increase the probability of developing AL by affecting tissue perfusion. Additionally, some studies have reported the utility of serum CRP levels for predicting postoperative inflammatory complications of oesophageal cancer before any clinical signs or symptoms appear [28-30].

Therefore, an accurate predictive model will help physicians assess the risk of $A L$ and provide timely interventions. In actuality, it is difficult to predict $\mathrm{AL}$ in individual patients due to uncontrollable factors, such as the type of surgical procedure. However, early assessment, suitable examinations and multi-faceted interventions may still be the most effective method for preventing AL.

\section{Limitations}

There are several limitations in our current study. First, the database was from a single, high-volume institute. Second, the study also has some limitations associated with its retrospective nature. Third, some prognostic parameters (such as pathological stage) and other important factors (such as drug history) were not included in our analysis. Finally, because external validation could not be conducted, we performed an internal validation using bootstrap testing.

\section{Conclusion}

A novel risk score for the prediction of AL using Sex, diabetes history, anastomotic type, reconstruction route, smoking history, CRP level and the presence of cardiac arrhythmia was developed and internally validated. This nomogram offers a useful tool for clinicians to assess the risk of AL in individuals after surgery. The model focuses on preoperative and intraoperative data, which can be acquired earlier and more easily. Additionally, a prospective and international study is required to further validate the new nomogram.

\section{Abbreviations \\ DM: Diabetes mellitus; ASA: American Society of Anesthesiologists; BMI: Body mass index; CRP: C-reactive protein; CVP: Central venous pressure; \\ LASSO: Least absolute shrinkage and selection operator; SE: Standard error}

\section{Acknowledgements}

The authors thank Zhigang Li, MD, in the Department of Esophageal Surgery, Shanghai Chest Hospital, Shanghai, China.

\section{Authors' contributions}

CHY helped in the data collection and analysis, and manuscript drafting. HXY helped in data collection and analysis, and revision of the manuscript. QH and HJL helped in data collection and analysis. MYX helped in the study design and critical revision of the manuscript. JXW conceived the study and 
helped in design, data analysis and interpretation, critical revision of the manuscript. All authors read and approved the final manuscript.

\section{Funding}

This work was supported by National Natural Science Foundation of China Project (81671078) and Shanghai Municipal Commission of Health and Family Planning Project (201840319).

\section{Availability of data and materials}

The datasets used and/or analysed during the current study are available from the corresponding author on reasonable request.

\section{Ethics approval and consent to participate}

This retrospective database analysis study was approved by the institutional review board of Shanghai Chest Hospital Ethics Committee, and the requirement to obtain informed consent was waived.

\section{Consent for publication}

Not applicable.

\section{Competing interests}

The authors declare that they have no competing interests.

Received: 10 June 2019 Accepted: 25 March 2020

Published online: 06 April 2020

\section{References}

1. Markar S, Gronnier C, Duhamel A, Bigourdan JM, Badic B, du Rieu MC, Lefevre JH, Turner K, Luc G, Mariette C. Pattern of postoperative mortality after esophageal Cancer resection according to center volume: results from a large European multicenter study. Ann Surg Oncol. 2015;22(8):2615-23.

2. Kassis ES, Kosinski AS, Ross P Jr, Koppes KE, Donahue JM, Daniel VC. Predictors of anastomotic leak after esophagectomy: an analysis of the society of thoracic surgeons general thoracic database. Ann Thorac Surg. 2013;96(6):1919-26.

3. Rutegard M, Lagergren P, Rouvelas I, Lagergren J. Intrathoracic anastomotic leakage and mortality after esophageal cancer resection: a populationbased study. Ann Surg Oncol. 2012;19(1):99-103.

4. Schuchert MJ, Abbas G, Nason KS, Pennathur A, Awais O, Santana M, Pereira R, Oostdyk A, Luketich JD, Landreneau RJ. Impact of anastomotic leak on outcomes after transhiatal esophagectomy. Surgery. 2010;148(4):831-8 discussion 838-840.

5. Van Daele E, Van de Putte D, Ceelen W, Van Nieuwenhove Y, Pattyn P. Risk factors and consequences of anastomotic leakage after Ivor Lewis oesophagectomydagger. Interact Cardiovasc Thorac Surg. 2016;22(1):32-7.

6. Zehetner J, DeMeester SR, Alicuben ET, Oh DS, Lipham JC, Hagen JA, DeMeester TR. Intraoperative assessment of perfusion of the gastric graft and correlation with anastomotic leaks after Esophagectomy. Ann Surg. 2015;262(1):74-8

7. Agzarian J, Visscher SL, Knight AW, Allen MS, Cassivi SD, Nichols FC, 3rd, Shen KR, Wigle D, Blackmon SH. The cost burden of clinically significant esophageal anastomotic leaks-a steep price to pay. J Thorac Cardiovasc Surg. 2019;157(5):2086-92.

8. Messager M, Warlaumont M, Renaud F, Marin H, Branche J, Piessen G, Mariette C. Recent improvements in the management of esophageal anastomotic leak after surgery for cancer. Eur J Surg Oncol. 2017:43(2):258-69.

9. Grimminger PP, Goense L, Gockel I, Bergeat D, Bertheuil N, Chandramohan SM, Chen KN, Chon SH, Denis C, Goh KL, et al. Diagnosis, assessment, and management of surgical complications following esophagectomy. Ann N Y Acad Sci. 2018;1434(1):254-73.

10. Jones CE, Watson TJ. Anastomotic leakage following Esophagectomy. Thorac Surg Clin. 2015;25(4):449-59.

11. Li B, Xiang J, Zhang Y, Hu H, Sun Y, Chen H. Factors affecting hospital mortality in patients with Esophagogastric anastomotic leak: a retrospective study. World J Surg. 2016;40(5):1152-7.

12. Wang $H$, Zhang L, Liu Z, Wang X, Geng S, Li J, Li T, Ye S. Predicting medication nonadherence risk in a Chinese inflammatory rheumatic disease population: development and assessment of a new predictive nomogram. Patient Prefer Adherence. 2018;12:1757-65.

13. Hijazi Z, Oldgren J, Lindback J, Alexander JH, Connolly SJ, Eikelboom JW, Ezekowitz MD, Held C, Hylek EM, Lopes RD, et al. The novel biomarker- based ABC (age, biomarkers, clinical history)-bleeding risk score for patients with atrial fibrillation: a derivation and validation study. Lancet. 2016; 387(10035):2302-11.

14. Van Calster B, Wynants L, Verbeek JFM, Verbakel JY, Christodoulou E, Vickers AJ, Roobol MJ, Steyerberg EW. Reporting and interpreting decision curve analysis: a guide for investigators. Eur Urol. 2018;74(6):796-804.

15. Sauerbrei $W$, Royston $P$, Binder $H$. Selection of important variables and determination of functional form for continuous predictors in multivariable model building. Stat Med. 2007;26(30):5512-28.

16. Haga $Y$, Wada $Y$, Takeuchi H, Ikejiri K, Ikenaga M. Prediction of anastomotic leak and its prognosis in digestive surgery. World J Surg. 2011;35(4):716-22.

17. Noble F, Curtis N, Harris S, Kelly JJ, Bailey IS, Byrne JP, Underwood TJ, South Coast Cancer C-O-G. Risk assessment using a novel score to predict anastomotic leak and major complications after oesophageal resection. J Gastrointest Surg. 2012;16(6):1083-95.

18. Bundred J, Hollis AC, Hodson J, Hallissey MT, Whiting JL, Griffiths EA. Validation of the NUn score as a predictor of anastomotic leak and major complications after Esophagectomy. Diseases of the esophagus : official journal of the International Society for Diseases of the Esophagus. 2020; 33(1). https://doi.org/10.1093/dote/doz041.

19. Cooke DT, Lin GC, Lau CL, Zhang L, Si MS, Lee J, Chang AC, Pickens A, Orringer MB. Analysis of cervical esophagogastric anastomotic leaks after transhiatal esophagectomy: risk factors, presentation, and detection. Ann Thorac Surg. 2009:88(1):177-84 discussion 184-175.

20. Briel JW, Tamhankar AP, Hagen JA, DeMeester SR, Johansson J, Choustoulakis E, Peters JH, Bremner CG, DeMeester TR. Prevalence and risk factors for ischemia, leak, and stricture of esophageal anastomosis: gastric pull-up versus colon interposition. J Am Coll Surg. 2004;198(4):536-41 discussion 541-532.

21. Dewar L, Gelfand G, Finley RJ, Evans K, Inculet R, Nelems B. Factors affecting cervical anastomotic leak and stricture formation following esophagogastrectomy and gastric tube interposition. Am J Surg. 1992; 163(5):484-9.

22. Walsh TN, Noonan N, Hollywood D, Kelly A, Keeling N, Hennessy TP. A comparison of multimodal therapy and surgery for esophageal adenocarcinoma. N Engl J Med. 1996;335(7):462-7.

23. Lin FC, Durkin AE, Ferguson MK. Induction therapy does not increase surgical morbidity after esophagectomy for cancer. Ann Thorac Surg. 2004; 78(5):1783-9.

24. National Health Commission Of The People's Republic Of C. Chinese guidelines for diagnosis and treatment of esophageal carcinoma 2018 (English version). Chinese J Cancer Res. 2019;31(2):223-58.

25. Urschel JD. Esophagogastrostomy anastomotic leaks complicating esophagectomy: a review. Am J Surg. 1995;169(6):634-40.

26. Pierie JP, de Graaf PW, van Vroonhoven TJ, Obertop H. Healing of the cervical esophagogastrostomy. J Am Coll Surg. 1999;188(4):448-54.

27. Okamura A, Watanabe M, Imamura Y, Kamiya S, Yamashita K, Kurogochi T, Mine S. Preoperative glycosylated hemoglobin levels predict anastomotic leak after Esophagectomy with cervical Esophagogastric anastomosis. World J Surg. 2017:41(1):200-7.

28. Warschkow R, Tarantino I, Ukegjini K, Beutner U, Muller SA, Schmied BM, Steffen T. Diagnostic study and meta-analysis of C-reactive protein as a predictor of postoperative inflammatory complications after gastroesophageal cancer surgery. Langenbeck's Arch Surg. 2012;397(5): 727-36

29. Aiolfi A, Asti E, Rausa E, Bonavina G, Bonitta G, Bonavina L. Use of C-reactive protein for the early prediction of anastomotic leak after esophagectomy: systematic review and Bayesian meta-analysis. PLoS One. 2018;13(12): e0209272.

30. Kano K, Aoyama T, Nakajima T, Maezawa Y, Hayashi T, Yamada T, Sato T, Oshima T, Rino Y, Masuda M, et al. Prediction of postoperative inflammatory complications after esophageal cancer surgery based on early changes in the $\mathrm{C}$-reactive protein level in patients who received perioperative steroid therapy and enhanced recovery after surgery care: a retrospective analysis. BMC Cancer. 2017;17(1):812.

\section{Publisher's Note}

Springer Nature remains neutral with regard to jurisdictional claims in published maps and institutional affiliations. 